\title{
Previdência e Taxa de Juros no Brasil ${ }^{*}$
}

\author{
Brian Bolarinwa Ogundairo ${ }^{\dagger}$ \\ Mauro Rodrigues $^{\dagger}$
}

\begin{abstract}
Sumário: 1. Introdução; 2. Fatos estilizados; 3. Modelo; 4. Análise quantitativa; 5. Conclusão; Apêndice.
Palavras-chave: Taxa de Juros Real, Previdência, Brasil, Gerações Sobrepostas.

Códigos JEL: $\quad$ E21, E43, H55.

O presente trabalho relaciona a alta taxa de juros real brasileira com o elevado gasto em previdência sob um regime de repartição. Para tanto, utilizamos uma versão padrão do modelo de gerações sobrepostas, com um regime de previdência misto (isto é, parte capitalização e parte repartição). O modelo é calibrado para a economia brasileira no período 2000-2014. Considera-se um estado estacionário inicial de modo a reproduzir a taxa de juros real média nesse período, sob um regime totalmente do tipo repartição. Simula-se então uma mudança para replicar os gastos em previdência do Chile, um país com um sistema majoritariamente do tipo capitalização. Em nossa especificação preferida, o modelo prevê uma queda de 1 ponto percentual na taxa de juros real (ao ano) de longo prazo. Isso corresponde a $18 \%$ do diferencial médio de juros entre Brasil e Chile no período $2000-2014$.
\end{abstract}

This paper studies how Brazil's high real interest rate is related to the country's payas-you-go (PAYG) pension system, which features exceptionally large expenses. We use a standard version of the overlapping generations model, with a mixed pension system (part PAYG part fully funded). We calibrate the model to the Brazilian economy between 2000 and 2014. We consider a steady state which reproduces the average real interest rate in this period, with a PAYG system. We then simulate a pension reform to replicate Chile's pension expenses. Like Brazil, Chile is a Latin American middle income country, but its pension system is mostly of the fully-funded type. In our preferred specification, the model predicts a 1 percentage point decrease in the long-run annual real interest rate. This corresponds to $18 \%$ of the average interest differencial between Brazil and Chile during the 2000-2014 period.

\footnotetext{
*Os autores agradecem ao PIBIC/CNPq pela bolsa de iniciação científica.

${ }^{\dagger}$ Graduado em Economia pela FEA/USP.

${ }^{\ddagger}$ Professor Associado. Departamento de Economia, Universidade de São Paulo (FEA/USP). Av. Prof. Luciano Gualberto, 908, Cidade Universitária, São Paulo, SP, Brasil. CEP 05508-010. Tel.+55 11 3091 6069. Email: mrodrigues@usp.br
} 


\section{INTRODUÇÃO}

O Brasil possui uma das taxas de juros reais mais altas do mundo. Este trabalho busca associar esse fato a outra especificidade brasileira: os elevados gastos com previdência. Em particular, o sistema previdenciário brasileiro é do tipo repartição, o qual tende a desestimular a poupança. Os trabalhadores hoje têm garantia de que receberão transferências no futuro, o que tende a reduzir o montante poupado privadamente. Entretanto, o esquema apenas transfere recursos de trabalhadores para aposentados, não contribuindo para a poupança agregada da economia. O resultado é uma menor oferta de fundos emprestáveis e, consequentemente, uma taxa de juros real mais elevada.

Lançamos mão de uma simples versão do modelo de gerações sobrepostas (Samuelson, 1958;Diamond, 1965), em que cada pessoa vive exatamente dois períodos. No primeiro período recebe renda do trabalho e contribui para o sistema previdenciário. Os recursos remanescentes são divididos entre consumo e poupança. A poupança é utilizada para acumular capital físico. No segundo período o indivíduo está aposentado; recebe juros da poupança (remuneração do capital) e transferências previdenciárias, que são utilizados unicamente para consumo. O sistema previdenciário é misto: parte repartição (com a arrecadação transferida aos aposentados no mesmo período) e parte capitalização (em que os recursos arrecadados são investidos em capital físico).

O modelo é calibrado para a economia brasileira entre 2000 e 2014, tendo como base um sistema de previdência unicamente do tipo repartição. Implementamos então uma reforma que transforma 0 sistema em misto. Nossa base de comparação é o Chile, que como o Brasil é um país latino-americano de renda média, mas que conta com um sistema predominantemente do tipo capitalização. O experimento de política no modelo assim emula os gastos em previdência chilenos, mantendo constantes todos os demais parâmetros. Nossa principal questão é: quanto seria a taxa real de juros brasileira, caso tivéssemos os mesmos gastos em previdência do Chile?

Em nossa calibração preferida (e relativamente conservadora), o modelo implica que a taxa real de juros brasileira (ao ano) seria cerca de 1 ponto percentual mais baixa no longo prazo. Colocado de outra forma, o mecanismo proposto pelo modelo explica cerca de $18 \%$ da diferença de taxa de juros entre Brasil e Chile. $O$ efeito, dessa forma, não é desprezível.

Na literatura temos diversas explicações para a elevada taxa de juros real no Brasil. Favero \& Giavazzi (2002) argumentam que a elevada dívida pública estaria por trás da especificidade brasileira. Já de acordo com Bacha, Holland \& Gonçalves (2007), a possibilidade de deter recursos em moeda estrangeira serviria como proteção a investidores contra o risco da moeda local. A ausência dessa modalidade no Brasil faria com que a taxa de juros tivesse que ser mais alta. Bacha (2010) levanta a hipótese de que nosso passado de hiperinflação e calotes seria também um canal relevante. Barboza (2015) analisa a importância da obstrução dos canais de transmissão da política monetária para a questão.

Outro ramo da literatura enfatiza o problema de poupança baixa no Brasil. Arida, Bacha \& LaraResende (2005) introduzem o conceito de incerteza jurisdicional, segundo o qual um viés anti-credor (presente principalmente no Executivo e Judiciário) previne o aparecimento de um mercado de crédito de longo prazo, diminuindo o incentivo a poupar. Hausmann (2008) e Franco (2011) argumentam que o fenômeno da baixa poupança está relacionado ao setor público, que competiria com o setor privado no mercado de fundos emprestáveis e, por conta dos elevados gastos e déficits, levaria a altas taxas reais de juros. Segura-Ubiergo (2012) encontra evidências de que não apenas a baixa poupança do governo, mas também a baixa poupança privada, ajudariam a explicar a especificidade brasileira. ${ }^{1}$

Nosso artigo segue essa linha, ao enfatizar os incentivos a poupar como determinantes das altas taxas de juros brasileiras. Mas aqui o mecanismo se dá pelos substanciais gastos previdenciários sob um sistema de repartição. Esse canal foi proposto anteriormente por Pessoa \& Nakane (2011). Nossa contribuição consiste em avaliar quantitativamente essa história, por meio de um modelo de equilíbrio

\footnotetext{
${ }^{1}$ Veja Barboza (2015) para uma revisão mais detalhada na literatura.
} 
tradicionalmente empregado em análises de impacto de sistemas previdenciários (Geanakoplos, 2008).

Nossa análise não implica que outros canais sejam irrelevantes para explicar as taxas de juros no Brasil. Quantitativamente, o mecanismo aqui estudado corresponde a uma parte relevante do diferencial de juros brasileiro (no caso, em relação ao Chile). Todavia, mesmo após levar em conta o sistema previdenciário, o modelo prevê taxas de juros menores, porém ainda bastante altas.

Há uma questão relacionada à nossa (e não menos importante), que trata do elevado spread bancário no Brasil - isto é, a diferença entre a taxa de juros paga pelo tomador e a taxa de juros recebida pelo depositante. Esse assunto conta com uma literatura acadêmica, ${ }^{2}$ porém não é o foco do presente trabalho, que se concentra em entender o nível da taxa de juros real brasileira.

0 restante do artigo está organizado da seguinte forma. A seção 2 introduz um conjunto de fatos estilizados sobre taxa de juros real e gastos com previdência no Brasil, em comparação a outros países. A seção 3 apresenta o modelo. A seção 4 contém nossa análise quantitativa, com a calibração, a análise do efeito do sistema previdenciário sobre os juros de longo prazo, e uma avaliação sobre os impactos dinâmicos de uma mudança na previdência. A seção 5 conclui.

\section{FATOS ESTILIZADOS}

O presente trabalho é motivado por duas características distintivas da economia brasileira: a elevada taxa real de juros, e os consideráveis gastos com previdência social. Primeiramente, expomos estatísticas referentes à taxa de juros brasileira, em comparação às de outros países. Optamos por evitar o período pré-2000, caracterizado por hiperinflação, seguido de uma estabilização com regime de câmbio controlado no caso brasileiro. Consideramos, assim, o período 2000-2014, para o qual dispomos de séries completas anuais de taxas de juros nominais (de Bancos Centrais) e taxas de inflação (baseadas em índices de preço ao consumidor) para 32 países mais a Zona do Euro. Os países são aqueles listados na Figura 1, além de Albânia, Armênia, Azerbaijão, Belize, Bulgária, Gana, Moldova, Nepal, Quirguistão, Suriname e Vietnã. Esse conjunto corresponde a cerca de 64\% do PIB mundial em 2010. Os dados são da base International Financial Statistics, do Fundo Monetário Internacional.

Evidentemente há diversas taxas de juros em uma economia. Optamos pelas taxas de Bancos Centrais com vistas a garantir maior comparabilidade entre países. Além disso, a taxa do Banco Central de um país (por afetar o custo do crédito) guarda relação próxima com taxas cobradas nas demais operações financeiras. Outras taxas de juros talvez sejam mais relevantes para as decisões de poupança e investimento (como rendimentos de aplicações financeiras e taxas de empréstimos para empresas), mas essas são também fortemente influenciadas pelo spread bancário que, como discutido na Introdução, não é o foco desse trabalho. Por esses motivos, realizaremos nossas comparações usando as taxas de juros de Bancos Centrais.

A Figura 1 mostra taxas de juros reais ex-post para 19 dos 32 países considerados (aqueles com PIB mais elevado), além da Zona do Euro. ${ }^{3}$ Exibem-se tanto médias como medianas para o período 2000-2014. Nota-se a elevada taxa de juros real média para o Brasil no período, rivalizando apenas com a Turquia. Entretanto, a elevada média da Turquia resulta de um valor discrepante no ano 2000. Ao compararmos as taxas medianas, a diferença do Brasil para os demais fica bem mais nítida. Na verdade, na amostra de 32 países mais a Zona do Euro, apenas Belize (um país muito pequeno) apresenta taxas média e mediana superiores às brasileiras.

A Figura 2 mostra a persistência da diferença dos juros brasileiros em relação aos demais países considerados. A comparação é feita ao longo do tempo, do Brasil contra a média ponderada dos demais,

\footnotetext{
${ }^{2}$ Veja, por exemplo, Afanasieff, Lhacer \& Nakane (2002), Souza-Sobrinho (2010), Dantas, de Medeiros \& Capelletto (2011), e Almeida \& Divino (2015).

${ }^{3} \mathrm{~A}$ taxa de juros real ex-post é dada por $(1+i) /(1+\pi)-1$, em que $i$ é a taxa de juros nominal (do Banco Central) e $\pi$ é a taxa de inflação.
} 
Figura 1. Taxa de juros reais ex-post (2000-2014), países selecionados.

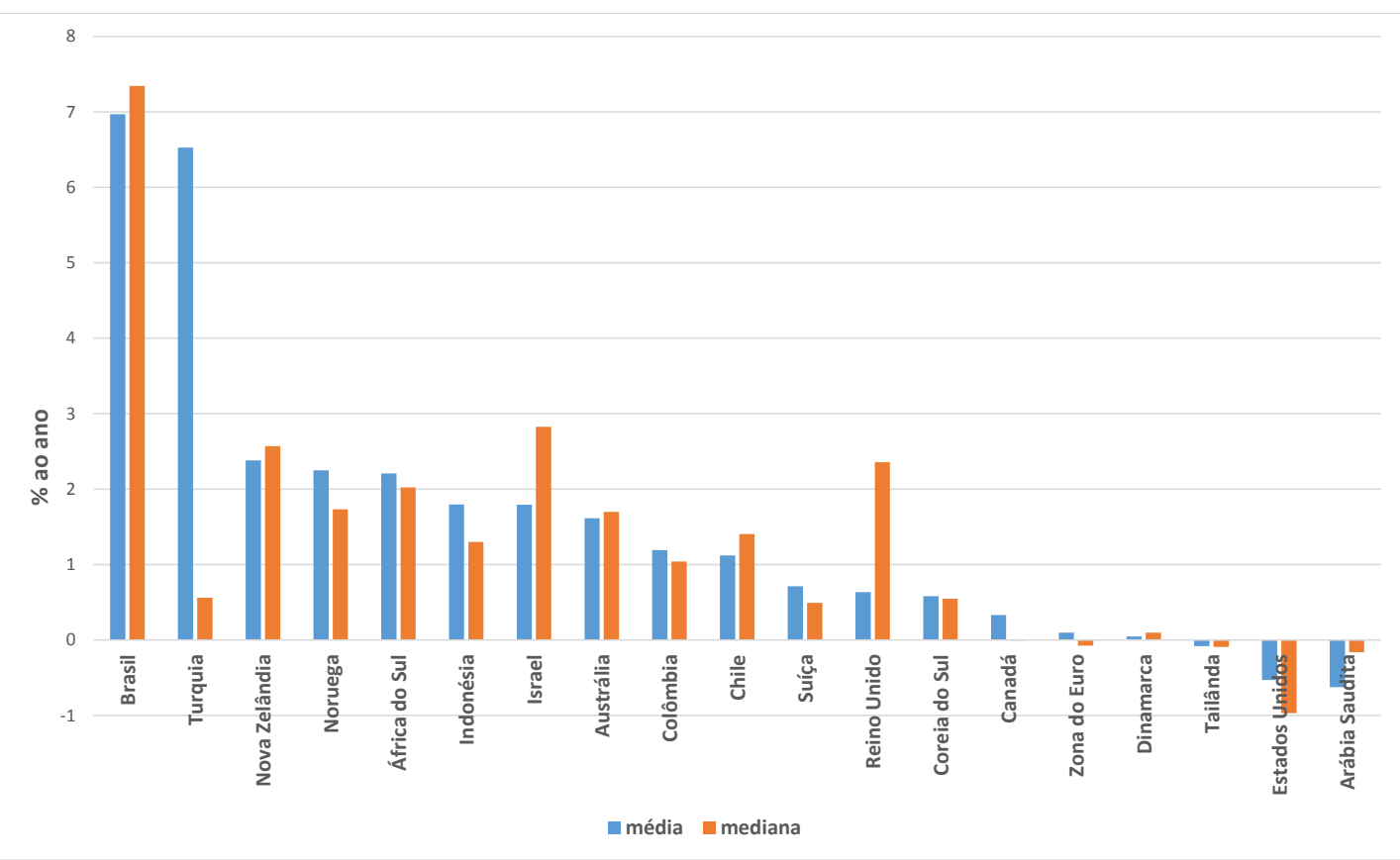

Figura 2. Taxa de juros reais ex-post (Brasil e média de 31 países + Zona do Euro).

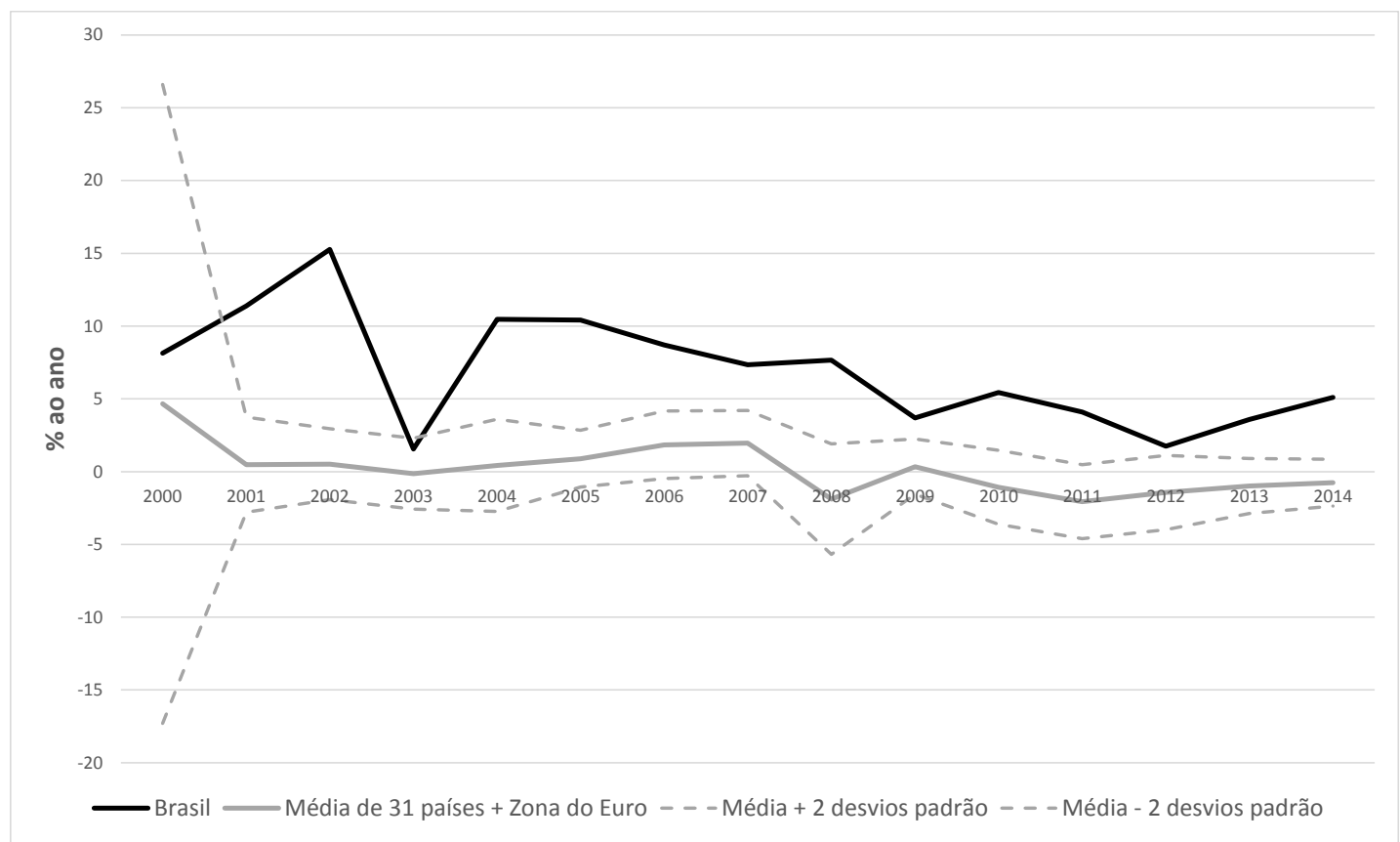


sendo os pesos dados pela participação de cada país no PIB mundial em 2010. Acrescentam-se também séries delimitando intervalos de mais 2 e menos 2 desvios padrões. A taxa real brasileira mantém-se bem acima da média dos demais no período todo, e frequentemente fora do intervalo de dois desvios padrões. ${ }^{4}$

O segundo conjunto de fatos estilizados diz respeito aos gastos com previdência no Brasil. A Figura 3 mostra um diagrama de dispersão contendo gastos em previdência como proporção do PIB contra a razão de dependência - no caso, o número de pessoas com mais de 65 anos dividido pelo número de pessoas em idade ativa ( 15 a 64 anos). Cada ponto corresponde a um país (o Brasil está destacado para enfatizar a comparação). Os dados são provenientes de Caetano \& Miranda (2007). Nota-se claramente uma associação positiva entre as duas variáveis, o que é esperado dado que países com uma fração maior de idosos tendem a gastar mais com aposentadorias.

O Brasil, entretanto, é claramente um ponto discrepante, estando bem acima da reta de regressão. Em outras palavras, apesar de possuir uma população ainda relativamente jovem, o país gasta com previdência (como proporção do PIB) valores comparáveis aos de países europeus como Holanda, Finlândia, Espanha e Alemanha, os quais têm uma participação muito maior de idosos em suas populações. ${ }^{5}$ Dentre os principais fatores citados na literatura para essa especificidade brasileira estão as elevadas taxas de reposição (benefícios previdenciários como fração da renda da pessoa ao longo da vida), ausência de idade mínima para aposentar (e consequentes baixas idades médias de aposentadoria), possibilidade de acumular benefícios, e ausência de condicionalidades para o recebimento e manutenção de benefícios. ${ }^{6}$

Figura 3. Gastos em previdência e razão de dependência.

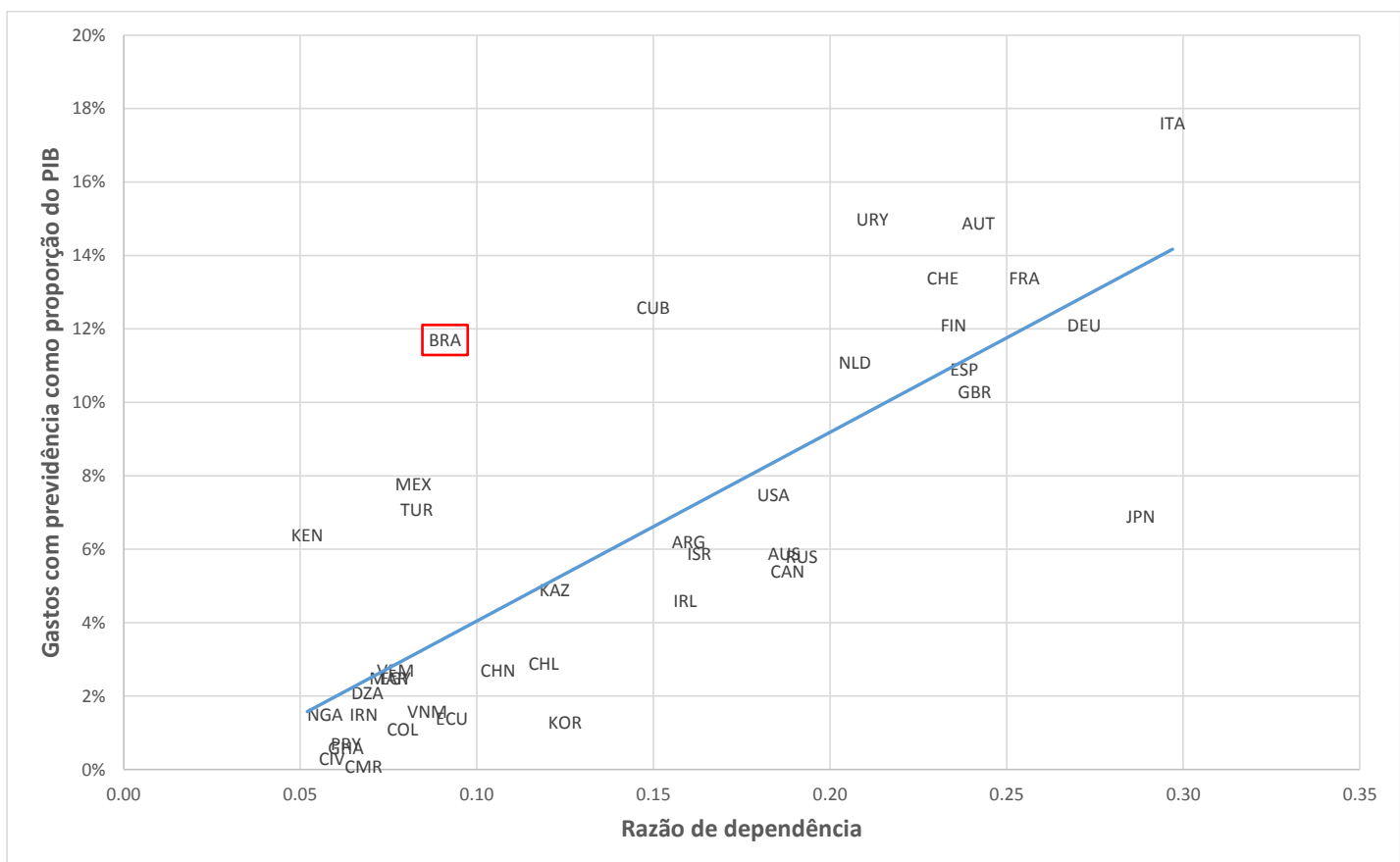

${ }^{4}$ O elevado desvio padrão em 2000 decorre do valor discrepante para a taxa de juros real da Turquia naquele ano.

${ }^{5}$ Esse fato foi documentado por diversos outros artigos (recorrendo a um diagrama de dispersão muito semelhante ao da Figura 3). Veja, por exemplo, Caetano \& Miranda (2007), Rocha \& Caetano (2008), Pessoa \& Nakane (2011) e Tafner (2012).

${ }^{6}$ Veja, por exemplo, Caetano \& Miranda (2007), Giambiagi \& Tafner (2010, 2011), e Tafner (2012). 


\section{MODELO}

Para entender a ligação entre taxa de juros e o sistema previdenciário, utilizamos uma simples versão do modelo de gerações sobrepostas, bastante similar às expostas por livros-textos de Macroeconomia moderna (por exemplo, Blanchard \& Fischer, 1989; Romer, 2006; Acemoglu, 2008). As pessoas vivem dois períodos. No primeiro período elas trabalham, pagam impostos, consomem e poupam para a aposentadoria. No segundo período estão aposentadas, e recebem juros da poupança e transferências previdenciárias. 0 sistema previdenciário é misto: parte repartição e parte capitalização. Na parte de repartição, os impostos arrecadados dos trabalhadores são transferidos para os aposentados no mesmo período. Na parte de capitalização, os recursos arrecadados são poupados, e entregues ao próprio indivíduo com juros quando ele se aposenta.

Há dois ativos: capital físico e um ativo financeiro. A taxa de juros dessa economia é o retorno do ativo financeiro o qual, por arbitragem, está atrelado ao retorno do capital. Como argumentamos a seguir, em equilíbrio o ativo financeiro não é transacionado, e seu retorno será tal que nenhum indivíduo está disposto a emprestar ou tomar emprestado. Tal ativo é introduzido no modelo apenas para tornar transparente o que entendemos por taxa de juros. Esta é uma economia fechada, sendo a taxa de juros determinada endogenamente de modo que as decisões de poupança e de investimento em capital físico sejam consistentes entre si.

\subsection{Preferências e restrições}

O tempo é discreto e indexado por $t=0,1,2, \ldots$ Não há incerteza. A cada período $t$, uma geração de $N_{t}$ indivíduos idênticos nasce. Cada pessoa vive exatamente dois períodos — juventude e velhice. Na juventude, a pessoa oferta 1 unidade de trabalho inelasticamente. Paga impostos sobre a renda do trabalho, os quais financiam o sistema previdenciário. A renda líquida de impostos é dividida entre consumo e poupança. Pode-se poupar tanto em capital físico como em um ativo financeiro. A restrição orçamentária de uma pessoa nascida em $t$ nessa mesma data é dada por

$$
C_{1 t}+S_{t}^{k}+S_{t}^{b}=\left(1-\tau_{t}^{p}-\tau_{t}^{f}\right) W_{t},
$$

em que $C_{1 t}$ é o consumo do indivíduo na juventude; $S_{t}^{k}$ é a poupança em capital físico; $S_{t}^{b}$ é a poupança no ativo financeiro; e $W_{t}$ é o salário. Na notação usada para consumo, o índice 1 denota período de juventude e o índice $t$ o tempo. A princípio consideramos um sistema de previdência misto, ou seja, parte repartição e parte capitalização. As alíquotas $\tau_{t}^{p}$ e $\tau_{t}^{f}$ são usadas para financiar a parcela de repartição (pay-as-you-go) e a parcela de capitalização (fully funded), respectivamente. Discutimos esses aspectos em detalhe mais adiante.

Na velhice, os indivíduos encontram-se aposentados e, portanto, não têm renda do trabalho. Suas fontes de recursos são o aluguel do capital, os juros sobre o ativo financeiro, e as transferências do governo via sistema previdenciário. Eles ainda liquidam seus ativos. Esses recursos são utilizados unicamente para consumo, dado que não há período adicional de vida. A restrição orçamentária do indivíduo nascido em $t$ quando aposentado (ou seja, em $t+1$ ) é portanto,

$$
C_{2 t+1}=\left[r_{t+1}+(1-\delta)\right] S_{t}^{k}+\left(1+R_{t+1}\right) S_{t}^{b}+T_{t+1}^{p}+T_{t+1}^{f},
$$

em que $C_{2 t+1}$ é o consumo do indivíduo na aposentadoria (o índice 2 denota o período de velhice); $r_{t+1}$ é a taxa de aluguel do capital físico; $R_{t+1}$ é a taxa de juros; $\delta$ é a taxa de depreciação do capital. Adicionalmente, $T_{t+1}^{p}$ e $T_{t+1}^{f}$ são transferências advindas respectivamente da parte de repartição e da parte de capitalização do sistema previdenciário. 
Os indivíduos extraem utilidade do consumo de cada período. A utilidade ao longo da vida é separável no tempo e do tipo CRRA:

$$
U_{t}=U\left(C_{1 t}, C_{2 t+1}\right)=\frac{C_{1 t}^{1-\gamma}-1}{1-\gamma}+\frac{1}{1+\theta} \frac{C_{2 t+1}^{1-\gamma}-1}{1-\gamma},
$$

sendo $\gamma>0$ a curvatura da função utilidade, e $\theta$ a taxa de desconto subjetiva. Cada pessoa nascida em $t$ escolhe $C_{1 t}, C_{2 t+1}, S_{t}^{k}$ e $S_{t}^{b}$, de modo a maximizar $U_{t}$, respeitando as restrições orçamentárias (1) e (2), e tomando como dados preços $\left(W_{t}\right.$ e $\left.r_{t+1}\right)$, alíquotas de imposto $\left(\tau_{t}^{p}\right.$ e $\left.\tau_{t}^{f}\right)$ e transferências $\left(T_{t+1}^{p}\right.$ e $\left.T_{t+1}^{f}\right)$.

Note que, em equilíbrio, a poupança no ativo financeiro $S_{t}^{b}$ deve ser igual a zero para todos os indivíduos. Primeiro, aposentados não estão interessados em emprestar recursos qualquer que seja a taxa de juros, dado que não estarão vivos em um próximo período para receber o principal mais os juros. Tampouco conseguem tomar emprestado, pois o emprestador sabe que não receberá os recursos de volta no futuro. Segundo, jovens não conseguem emprestar/tomar emprestado entre si pois são idênticos. Se um jovem emprestasse (tomasse emprestado) recursos, então todos os demais também estariam com posição positiva (negativa) em tal ativo, o que certamente não é um equilíbrio. Logo, a única situação consistente com equilíbrio nessa economia é $S_{t}^{b}=0$.

A motivação para introduzir o ativo financeiro no modelo é simplesmente tornar transparente a taxa de juros $\left(R_{t}\right)$, nosso principal objeto de estudo. Em particular, $R_{t}$ deve ser tal que $S_{t}^{b}=0$. Note que os indivíduos estão interessados apenas no retorno de cada ativo. Como não há incerteza, para que haja solução interior na escolha de portfólio, os retornos dos dois ativos devem ser iguais, ou seja:

$$
R_{t}=r_{t}-\delta
$$

Dadas essas condições de equilíbrio, resolvemos o modelo ignorando o ativo financeiro. Depois determinamos o aluguel do capital de equilíbrio e utilizamos a equação (3) para encontrar a taxa de juros dessa economia. A escolha ótima de consumo nos dois períodos e investimento em capital físico é sumarizada pela seguinte condição de primeira ordem:

$$
C_{1 t}^{-\gamma}=C_{2 t+1}^{-\gamma} \frac{r_{t+1}+(1-\delta)}{1+\theta},
$$

em que o lado esquerdo representa o custo marginal (em termos de utilidade do consumo em $t$ ) de investir em capital físico. Já o lado direito representa o benefício marginal dessa ação: para cada unidade investida em $t$ recupera-se $o$ aluguel do capital em $t+1$, mais a parte não depreciada do capital, ou seja, $r_{t+1}+(1-\delta)$. Esse valor multiplicado por $C_{2 t+1}^{-\gamma}$ fornece o benefício marginal em termos de utilidade no futuro. Finalmente, ao dividi-lo por $1+\theta$, tem-se o benefício marginal no futuro, em unidades de utilidade no presente, o qual é comparável com o custo marginal hoje. No ótimo, custo marginal e benefício marginal devem ser iguais.

\subsection{Tecnologia}

Há um único produto homogêneo $\left(Y_{t}\right)$, gerado por uma firma competitiva que combina capital $\left(K_{t}\right)$ e trabalho $\left(N_{t}\right)$ por meio de uma função de produção Cobb-Douglas com retornos constantes de escala:

$$
Y_{t}=K_{t}^{\alpha}\left(A_{t} N_{t}\right)^{1-\alpha}, \quad 0<\alpha<1,
$$

em que $A_{t}$ é um índice de eficiência tecnológica, que cresce ao longo do tempo. $O$ insumo capital é provido pelos aposentados em $t$, que acumularam esse ativo durante seus períodos de juventude. Já $o$ trabalho é provido pelos jovens, que se encontram em idade ativa. Como a oferta de trabalho é inelástica, a quantidade de trabalho acima é igual ao tamanho da geração nascida em $t$. 
O produto é o numerário dessa economia. Por conta da hipótese de concorrência perfeita, a firma escolhe as quantidades de capital e trabalho de modo a igualar o preço de cada insumo ao seu produto marginal:

$$
\begin{aligned}
r_{t} & =\alpha K_{t}^{\alpha-1}\left(A_{t} N_{t}\right)^{1-\alpha}=\alpha k_{t}^{\alpha-1} \\
W_{t} & =(1-\alpha) A_{t} K_{t}^{\alpha}\left(A_{t} N_{t}\right)^{-\alpha}=(1-\alpha) A_{t} k_{t}^{\alpha},
\end{aligned}
$$

sendo $k_{t} \equiv K_{t} /\left(A_{t} N_{t}\right)$ o capital por trabalhador-eficiência. O produto é dividido entre consumo e investimento $\left(I_{t}\right)$. Esse último eleva o estoque de capital ao longo do tempo, de acordo com a seguinte regra:

$$
K_{t+1}=(1-\delta) K_{t}+I_{t} .
$$

$\mathrm{O}$ número de trabalhadores cresce à taxa exógena $n$. $\mathrm{O}$ índice de eficiência cresce à taxa de progresso técnico $g$, também exógena:

$$
\frac{N_{t+1}}{N_{t}}=1+n, \quad \frac{A_{t+1}}{A_{t}}=1+g .
$$

\subsection{Previdência}

Como mencionado acima, inserimos previdência no modelo por meio de um sistema misto: parte repartição e parte capitalização. Na parcela correspondente a repartição, o governo taxa uma fração $\tau_{t}^{p}$ da renda dos indivíduos em idade ativa em $t$ e a transfere para os aposentados nesse mesmo período. $O$ montante arrecadado é dividido igualmente entre todos os aposentados, de modo que a transferência por aposentado (referente à parcela de repartição do sistema) seja dada por:

$$
T_{t}^{p}=\frac{N_{t} \tau_{t}^{p} W_{t}}{N_{t-1}}=(1+n) \tau_{t}^{p} W_{t},
$$

em que $N_{t} \tau_{t}^{p} W_{t}$ é o montante arrecadado, e $N_{t-1}$ é o número de aposentados em $t$ (isto é, o tamanho da geração nascida em $t-1$ ). Na parcela referente a capitalização, temos um esquema de poupança forçada: o governo retira recursos da geração nascida em $t$ quando jovem, investe em capital, e transfere o aluguel de tal capital mais o capital remanescente (após depreciação) a essa mesma geração em $t+1$. Logo, a transferência por aposentado em $t+1$ é

$$
T_{t+1}^{f}=\tau_{t}^{f} W_{t}\left[r_{t+1}+(1-\delta)\right] .
$$

Ao contrário da parte de repartição, aqui o governo investe os recursos arrecadados, e não apenas os transfere entre gerações. Trataremos as alíquotas $\tau_{t}^{p}$ e $\tau_{t}^{f}$ como exógenas, sendo mudanças nas mesmas interpretadas como alterações no sistema previdenciário no modelo. As transferências $T_{t}^{p}$ e $T_{t}^{f}$ são, assim, determinadas endogenamente em função das alíquotas.

Em nosso modelo, a única função do governo é administrar o sistema previdenciário. Além disso, estamos supondo orçamento equilibrado, isto é, o valor total arrecadado é sempre igual ao valor total dos benefícios previdenciários concedidos. No Brasil, entretanto, a previdência é deficitária, sendo a diferença entre despesas e receitas coberta com recursos do Tesouro Nacional. Por exemplo, no ano de 2015, a diferença entre total de benefícios e arrecadação correspondeu a cerca de $3 \%$ do PIB. ${ }^{7}$

Essa característica poderia ser incorporada no modelo pela introdução de outros impostos, que financiariam a diferença entre despesas e receitas do sistema de previdência. Em particular, se esses

\footnotetext{
${ }^{7}$ Dados do Boletim Estatístico da Previdência Social (janeiro de 2016), Ministério do Trabalho e Previdência Social. Valores se referem à soma do INSS e RGPS.
} 
impostos incidirem integralmente sobre a renda do trabalho, nossos resultados se mantêm inalterados. ${ }^{8}$ Alternativamente, pode-se supor que há outros gastos no modelo (por exemplo, para a provisão de um bem público), que deveriam ser reduzidos por conta do déficit previdenciário.

Tais aspectos são de fato relevantes, porém optamos não inclui-los em nossa análise, pois estamos interessados em entender o impacto do sistema previdenciário sobre os incentivos a poupar e a taxa de juros real de equilíbrio. A inclusão de impostos e gastos públicos poderia trazer outros efeitos sobre os objetos analisados, que não estão diretamente relacionados ao mecanismo que queremos enfatizar nesse artigo.

\subsection{Equilíbrio}

Como esta é uma economia fechada, em equilíbrio o investimento é igual à poupança total. Essa última é composta por três partes, apresentadas no lado direito da equação abaixo: a poupança voluntária dos jovens em $t\left(N_{t} S_{t}^{k}\right)$, a poupança forçada desses mesmos jovens via parte de capitalização do sistema previdenciário $\left(N_{t} \tau_{t}^{f} W_{t}\right)$, e a despoupança dos aposentados em $t$, que estão liquidando o capital remanecente após depreciação $\left((1-\delta) K_{t}\right)$,

$$
I_{t}=N_{t} S_{t}^{k}+N_{t} \tau_{t}^{f} W_{t}-(1-\delta) K_{t} .
$$

Essa equação completa a descrição do modelo. No restante desta subseção, obteremos uma expressão para a lei de movimento do capital, que caracteriza a evolução dessa variável ao longo do tempo dada uma condição inicial.

Como $A_{t}$ e $N_{t}$ crescem no tempo, a lei de movimento aqui encontrada diz respeito ao equivalente estacionário do capital, isto é, $k_{t}=K_{t} /\left(A_{t} N_{t}\right)$. Usando (7) e (11), segue que

$$
K_{t+1}=N_{t}\left(S_{t}^{k}+\tau_{t}^{f} W_{t}\right)=N_{t} W_{t}\left(s_{t}^{k}+\tau_{t}^{f}\right),
$$

sendo $s_{t}^{k}=S_{t}^{k} / W_{t}$. Dividindo os dois lados por $A_{t} N_{t}$,

$$
\frac{K_{t+1}}{A_{t+1} N_{t+1}} \frac{A_{t+1} N_{t+1}}{A_{t} N_{t}}=w_{t}\left(s_{t}^{k}+\tau_{t}^{f}\right),
$$

em que $w_{t}=W_{t} / A_{t}$. Usando (6) e (8),

$$
k_{t+1}=\frac{1}{(1+n)(1+g)}\left(s_{t}^{k}+\tau_{t}^{f}\right)(1-\alpha) k_{t}^{\alpha} .
$$

Para obter uma expressão para $s_{t}^{k}$, substitua (1), (2), (9) e (10) em (4):

$$
\left[\frac{\left(1-\tau_{t}^{p}-\tau_{t}^{f}\right) W_{t}-S_{t}^{k}}{\left(r_{t+1}+(1-\delta)\right) S_{t}^{k}+(1+n) \tau_{t+1}^{p} W_{t+1}+\tau^{f} W_{t}\left(r_{t+1}+(1-\delta)\right)}\right]^{-\gamma}=\frac{r_{t+1}+(1-\delta)}{1+\theta} .
$$

Logo

$$
s_{t}^{k}=\frac{\left(1-\tau_{t}^{p}\right)\left(\frac{r_{t+1}+(1-\delta)}{1+\theta}\right)^{1 / \gamma}-\tau_{t+1}^{p} \frac{W_{t+1}}{W_{t}}(1+n)}{\left(r_{t+1}+1-\delta\right)+\left(\frac{r_{t+1}+(1-\delta)}{1+\theta}\right)^{1 / \gamma}}-\tau_{t}^{f} .
$$

\footnotetext{
${ }^{8}$ Suponha, por simplicidade, que o sistema é inteiramente do tipo repartição, e a alíquota para financiá-lo é $\tau_{0}^{p}$. Essa alíquota é insuficiente, sendo necessário outro imposto. Se esse imposto incidir sobre a renda do trabalho — por exemplo, com alíquota $\theta$ - teremos que a alíquota total sobre a renda do trabalho será $\tau_{0}^{p}+\theta$. Isso é equivalente a supor que há um único imposto com alíquota $\tau_{0}^{p}+\theta$, que garante orçamento equilibrado no sistema, tal como no nosso modelo.
} 
Usando (5), (6) e (8) na equação acima, e substituindo em (12), pode-se encontrar a lei de movimento de $k$, apenas em termos dos parâmetros do modelo:

$$
k_{t+1}=\frac{1-\alpha}{(1+n)(1+g)} \frac{\left(1-\tau_{t}^{p}\right)\left(\frac{\alpha k_{t+1}^{\alpha-1}+(1-\delta)}{1+\theta}\right)^{1 / \gamma}-\tau_{t+1}^{p}(1+n)(1+g)\left(\frac{k_{t+1}}{k_{t}}\right)^{\alpha}}{\left(\alpha k_{t+1}^{\alpha-1}+1-\delta\right)+\left(\frac{\alpha k_{t+1}^{\alpha-1}+(1-\delta)}{1+\theta}\right)^{1 / \gamma}} k_{t}^{\alpha} .
$$

A expressão acima define implicitamente uma relação entre $k_{t+1}$ e $k_{t}$, dados os parâmetros da economia, isto é, $k_{t+1}=\phi\left(k_{t}\right)$. Dada uma condição inicial $k_{0}$ é possível encontrar toda a trajetória futura de $k$ e, com base nisso, utilizar as demais equações do modelo para determinar as prin cipais variáveis dessa economia.

\subsection{Estado estacionário}

Nosso principal interesse consiste em entender o efeito do sistema previdenciário sobre a taxa de juros de longo prazo. Para tanto focaremos em estados estacionários, tomando $\tau^{p}$ constante no tempo. Em particular, o estado estacionário pode ser calculado a partir da equação (14), considerando $k_{t+1}=$ $k_{t}=k^{*}$.

Idealmente gostaríamos de ter um único estado estacionário com capital positivo, que seja também estável. Dessa forma, para qualquer condição inicial $k_{0}>0$, a economia convergiria para esse estado estacionário ao longo do tempo. Entretanto, por conta de nossas hipóteses, não é possível obter essa propriedade analiticamente. ${ }^{9}$ No presente trabalho, isso foi checado numericamente para a versão calibrada do modelo. Em todas as combinações de parâmetros avaliadas, para dado $\tau^{p}$, há um único estado estacionário com capital positivo, o qual é estável. Como estamos avaliando o impacto do sistema previdenciário, compararemos valores de $k^{*}-\mathrm{e}$, consequentemente, a produtividade marginal do capital e a taxa de juros real de longo prazo - que podem ser obtidos a partir de diferentes configurações de alíquotas $\tau^{f}$ e $\tau^{p}$.

Note, da equação (14), que a lei de movimento não é afetada pela alíquota $\tau_{t}^{f}$. Isso é esperado, uma vez que a poupança voluntária e a poupança forçada são substitutos perfeitos para o indivíduo — elas têm o mesmo retorno, pois se tratam de investimento em capital físico. Se o governo força o indivíduo a poupar 1 unidade a mais pelo sistema previdenciário (na parte de capitalização), ele diminui sua poupança voluntária em exatamente 1 unidade, de modo que a poupança total dessa economia permaneça inalterada. ${ }^{10}$

Já $\tau^{p}$ afeta negativamente a poupança dessa economia e, consequentemente, o estoque de capital de longo prazo. Como há expectativa de que o governo transferirá recursos no futuro para a pessoa, ela não terá tanta necessidade de poupar para garantir o consumo na aposentadoria. Um aumento em $\tau^{p}$ provoca, portanto, redução na poupança voluntária dos jovens. No entanto, esses recursos da parte de repartição do sistema não são poupados pelo governo, e sim transferidos para os aposentados no presente. Em outras palavras, há diminuição na poupança privada, sem contrapartida de aumento na poupança do governo, o que reduz a poupança total na economia.

Isso leva a queda no estoque de capital de longo prazo, e consequente elevação no produto marginal desse insumo. Em equilíbrio temos portanto um aumento no aluguel do capital e na taxa de juros dessa economia. O modelo, assim, estabelece uma ligação entre o sistema previdenciário do tipo repartição e a taxa de juros de longo prazo. Na próxima seção calibramos o modelo para a economia brasileira e avaliamos quantitativamente esse efeito.

\footnotetext{
${ }^{9}$ Esse problema é característico do modelo de gerações sobrepostas, mesmo nas versões mais simples. Veja Romer (2006, pp.84-87).

${ }^{10}$ Entretanto, se $\tau_{t}^{f}$ for muito elevado, a poupança privada será igual a zero, de modo que elevações adicionais nesse parâmetro causam aumento na poupança total. Em nossos exercícios quantitativos supomos que $\tau_{t}^{f}$ nunca é alto o suficiente para zerar a poupança privada.
} 


\section{ANÁLISE QUANTITATIVA}

\subsection{Calibração}

Cada período no modelo corresponde a 30 anos. Alguns parâmetros do modelo são calibrados com base na literatura, enquanto outros são escolhidos com vistas a reproduzir estatísticas da economia brasileira a partir da década de 2000 . Com relação à taxa de depreciação, valores usuais literatura (em torno de $5 \%$ ao ano) implicam que uma unidade de capital está completamente depreciada dentro de um período de 30 anos. Por conta disso, fixamos $\delta=1$. O parâmetro $\alpha$, que corresponde à participação do capital na renda total dessa economia, é fixado em 0,4 , seguindo Gomes, Pessôa \& Veloso (2003).

A literatura adota valores diversos para o parâmetro $\gamma$. Aqui escolhemos o valor $\gamma=1$ (isto é, utilidade $\log$ ), que é consistente com o utilizado pela literatura de RBC (veja, por exemplo, Cooley \& Prescott, 1995; Jones, Manuelli \& Siu, 2000). Entretanto, estimativas desse parâmetro com base em preços de ativos financeiros produzem valores bem maiores (veja Guvenen, 2006, para uma discussão). Por conta disso, realizamos experimentos com valores alternativos, tipicamente utilizados na literatura $(\gamma=2 \mathrm{e}$ $\gamma=5$ ). Adotamos a calibração com $\gamma=1$ como preferida (explicado a seguir). Esta especificação é, na verdade, conservadora no que toca ao impacto de mudanças previdenciárias sobre a taxa de juros, em comparação aos efeitos encontrados para valores mais elevados de $\gamma$.

Os parâmetros $n$ e $g$ são escolhidos de modo a reproduzir as taxas médias de crescimento da população e da renda real per capita da economia brasileira no período 2000-2014. Tais taxas médias são respectivamente $1,23 \%$ e $2,06 \%$ ao ano, e implicam $n=0,4430$ e $g=0,8436$ no horizonte de 30 anos do modelo. ${ }^{11}$

Consideramos uma economia inicialmente em estado estacionário com um regime previdenciário unicamente do tipo repartição. A alíquota $\tau^{p}$ é escolhida de modo a reproduzir os gastos com previdência como proporção do PIB para o Brasil $(11,7 \%){ }^{12}$ Isso implica $\tau^{p}=0,195$. Finalmente, a taxa de desconto subjetiva $\theta$ é fixada com vistas a replicar a taxa de juros real de $6,97 \%$ por ano, que corresponde à média para o Brasil no período 2000-2014 (veja a seção 2). Dada a escolha dos demais parâmetros, o valor do parâmetro é $\theta=0,8771$. O Apêndice descreve os detalhes da calibração de $\theta$, como função de tal valor para a taxa de juros e dos demais parâmetros do modelo. A Tabela 1 sumariza os valores selecionados para os parâmetros.

Tabela 1. Valores dos parâmetros.

\begin{tabular}{clc}
\hline Parâmetro & Descrição & Valor \\
\hline$\delta$ & Taxa de depreciação & 1 \\
$n$ & Taxa de crescimento populacional & 0,4430 \\
$g$ & Taxa de progresso técnico & 0,8436 \\
$\alpha$ & Parâmetro da função de produção & 0,4 \\
$\gamma$ & Curvatura da função utilidade & 1 \\
$\tau^{p}$ & Alíquota de imposto sobre a renda do trabalho & 0,195 \\
$\theta$ & Taxa de desconto subjetiva & 0,8771 \\
\hline
\end{tabular}

${ }^{11}$ Dados da World Economic Outlook Database (FMI).

${ }^{12}$ Esse valor provém de Caetano \& Miranda (2007), e é o mesmo que consta na Figura 3. 


\subsection{Sistema previdenciário: implicações de longo prazo}

Primeiramente analisamos os efeitos de longo prazo de uma mudança no sistema previdenciário. Simulamos no modelo uma reforma que altera o sistema, reduzindo a parte de repartição e passando a incorporar uma parte de capitalização. Compararemos o caso brasileiro com o do Chile, um país que realizou uma reforma radical na década de 1980, adotando um sistema do tipo capitalização. Especificamente, os trabalhadores passaram a depositar (compulsoriamente) uma fração de suas rendas em contas individuais, que poderiam ser resgatadas com juros no momento da aposentadoria. 0 sistema chileno, entretanto, possui ainda uma pequena parcela na forma de repartição. ${ }^{13}$ De acordo com Caetano \& Miranda (2007), os gastos com previdência do Chile correspondem a 2,9\% do PIB daquele país.

Estamos interessados em responder as seguintes perguntas: se alterarmos a alíquota $\tau^{p}$ do Brasil para reproduzir aquela praticada no Chile, porém mantendo todos os demais parâmetros, o que aconteceria com a taxa de juros real de longo prazo? Quanto desse movimento explica a diferença observada de taxa de juros entre Brasil e Chile? Como demonstrado na seção anterior, a alíquota $\tau^{f}$ não altera os resultados agregados para poupança, acumulação de capital e taxa de juros. Não é necessário, assim, estipular a alíquota $\tau^{f}$ no novo sistema de previdência.

Simulamos então, no modelo, uma mudança que altera o parâmetro $\tau^{p}$ para reproduzir os gastos com previdência como no Chile — no caso, o novo valor de $\tau^{p}$ é 0,0483 . Todos os demais parâmetros são mantidos constantes. Para analisar o efeito de longo prazo, comparam-se aqui dois estados estacionários, com os diferentes valores de $\tau^{p}$. Avaliamos também o impacto de uma alteração mais radical, em que 0 sistema previdenciário torna-se totalmente do tipo capitalização (ou seja, $\tau^{p}=0$ ). Os resultados para a taxa de juros (em termos anuais) estão na Tabela 2. Lembre-se que o modelo está calibrado de modo a reproduzir uma taxa de juros inicial de 6,97\% para $\tau^{p}=0,195$ (que representa o cenário brasileiro). ${ }^{14}$

No caso de $\gamma=1$ (coluna (1)), nossos resultados indicam que, caso o Brasil adotasse um regime previdenciário que emulasse os dados do Chile, a taxa de juros real seria de 5,92\% — ou seja, cerca de um 1 ponto percentual a menos do que a atual. Nos dados a diferença de taxa de juros entre Brasil e Chile é de $6,97 \%-1,12 \%=5,85 \%$. Em outras palavras, para essa configuração de parâmetros, o mecanismo proposto pelo modelo é capaz de explicar aproximadamente $18 \%$ do diferencial de juros entre os dois países.

Quando tornamos o sistema previdenciário totalmente do tipo capitalização $\left(\tau^{p}=0\right)$, a queda dos juros é ainda maior. Isso ocorre porque, nesse caso, o aumento na poupança total seria mais forte,

Tabela 2. Sistema previdenciário e taxa de juros de longo prazo.

\begin{tabular}{cccc}
\hline & $\begin{array}{c}\gamma=1 \\
(1)\end{array}$ & $\begin{array}{c}\gamma=2 \\
(2)\end{array}$ & $\begin{array}{c}\gamma=5 \\
(3)\end{array}$ \\
\hline $\begin{array}{c}\tau^{p}=0,195 \\
(\text { Brasil) } \\
\tau^{p=0,048} \\
(\text { Chile) }\end{array}$ & $6,97 \%$ & $6,97 \%$ & $6,97 \%$ \\
$\tau^{p}=0$ & $5,92 \%$ & $5,43 \%$ & $5,92 \%$ \\
\hline
\end{tabular}

\footnotetext{
${ }^{13}$ Veja, por exemplo, Diamond (1993) e Kritzer (2008).

${ }^{14} \mathrm{O}$ modelo produz taxas de juros que correspondem a um período de 30 anos. Na Tabela 2 reportamos o equivalente anual dessas taxas.
} 
induzindo maior acumulação do capital, e redução na produtividade marginal desse ativo.

As colunas (2) e (3) mostram simulações para $\gamma=2$ e $\gamma=5$. Um valor mais elevado para $\gamma$ significa que os indivíduos tornam-se menos tolerantes a variações de consumo ao longo da vida. Como inicialmente eles têm uma renda elevada garantida na aposentadoria, isso os faz mais relutantes a transferir recursos para o futuro, o que (tudo mais constante) elevaria a taxa de juros de equilíbrio. Para assegurar que a taxa de juros inicial seja $6,97 \%$, é preciso recalibrar o modelo e reduzir o valor de $\theta$.

Dessa forma, nas colunas (2) e (3) temos tanto um aumento em $\gamma$, como uma redução em $\theta$. Essa combinação torna os indivíduos mais sensíveis a variações na renda garantida no futuro, que é reduzida com a mudança no sistema previdenciário. Em outras palavras, a reação da poupança privada tende a ser mais forte nas demais colunas da Tabela 2, o que propicia quedas maiores nas taxas de juros. Por exemplo, para $\tau^{p}=0,048$ (gastos previdenciários do Chile) e $\gamma=5$, obtém-se uma queda adicional de 1 ponto percentual na taxa de juros de longo prazo. ${ }^{15}$

Tais valores de $\gamma$, todavia, implicam valores negativos de $\theta$, além de levar variações pouco plausíveis na taxa de poupança da economia - por exemplo, quando $\gamma=5$, a taxa de poupança aumenta em cerca de 10 pontos percentuais. Dessa forma, decidimos por uma especificação mais conservadora, e adotamos como preferida aquela com $\gamma=1$.

\subsection{Transições}

Para prover um pouco mais de intuição sobre os impactos da mudança no sistema previdenciário, nessa subseção avaliamos os efeitos dinâmicos da redução em $\tau^{p}$. Focamos no caso $\gamma=1$ e uma diminuição em $\tau^{p}$ para reproduzir as estatísticas do Chile. Há diversas maneiras de implementar a alteração no sistema ao longo do tempo. Aqui supomos que a mudança é anunciada em $t=0$, e realizada ao longo dos próximos $M$ períodos. A redução em $\tau^{p}$ é feita de maneira linear no tempo, até alcançar a nova alíquota definitiva no período $M$.

Avaliamos dois cenários: (i) uma mudança brusca, sendo todo o ajuste realizado em 1 período $(M=1)$, o que implica $\tau_{t}^{p}=0,195$ em $t=0$, e $\tau_{t}^{p}=0,048$ para $t \geq 1$; e (ii) uma mudança mais gradual, que ocorre ao longo de três períodos $(M=3)$, isto é, $\tau_{0}^{p}=0,195, \tau_{1}^{p}=0,146, \tau_{2}^{p}=0,097$, e $\tau_{t}^{p}=0,048$ para $t \geq 3$. A Figura 4 mostra as trajetórias do capital, poupança (como fração da renda do jovem), consumo no primeiro período de vida e consumo no segundo período de vida. ${ }^{16}$ As trajetórias refletem apenas o nível das variáveis, isto é, descontam-se as respectivas taxas de crescimento de longo prazo. Exceto para a poupança, o nível inicial de cada variável é normalizado em 100.

Focando inicialmente no caso $M=1$, a geração nascida no momento da alteração continua pagando impostos altos, porém receberá benefícios menores no futuro por conta da redução de $\tau^{p} \cdot{ }^{17}$ Isso provoca uma queda na renda desses indivíduos ao longo da vida, fazendo-os reduzir tanto consumo quando jovens, como na aposentadoria. Além disso, como a queda de recursos disponíveis é maior no segundo período - resultado da diminuição da transferência previdenciária —, tais consumidores passam a poupar mais para diminuir a flutuação de consumo no tempo. Consequentemente, o estoque de capital cresce ao longo do tempo.

Isso provoca elevação dos salários, permitindo que as gerações futuras aumentem seus consumos nos dois períodos de vida. Note, entretanto, que $C_{1}$ cresce mais do que $C_{2}$ ao longo da transição. Isso

\footnotetext{
${ }^{15}$ Nessa explicação sobre os mecanismos do modelo, estamos implicitamente supondo que $\tau^{p}$ é reduzido, sem alteração correspondente em $\tau^{f}$, de modo que a transferência no segundo período de vida diminua. Como vimos, isso não acarreta perda de generalidade, pois o valor de $\tau^{f}$ não afeta poupança, investimento e taxa de juros de equilíbrio no modelo.

${ }^{16}$ No modelo, a poupança como fração da renda do jovem é $s_{t}^{k}=S_{t}^{k} / W_{t}$.

${ }^{17}$ Novamente, para essa explicação, estamos supondo diminuição em $\tau^{p}$, sem alteração correspondente em $\tau^{f}$, de modo que a transferência no segundo período de vida diminua. Isso não acarreta perda de generalidade. Veja nota de rodapé 15.
} 
Figura 4. Transições.
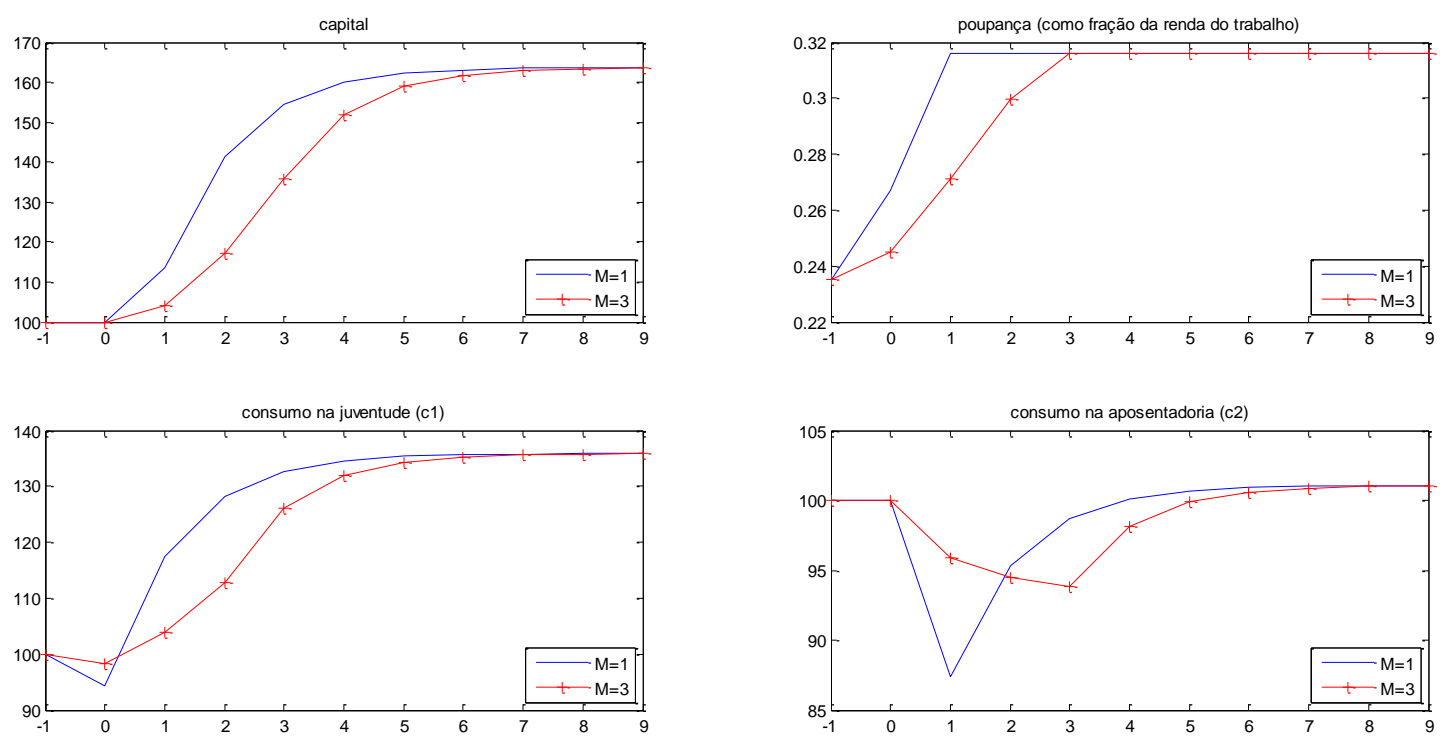

ocorre porque a taxa de juros real segue uma trajetória descendente, levando os indivíduos a postergarem menos consumo ao longo de suas vidas. No longo prazo, capital, poupança (como fração do salário), e consumo em ambos os períodos são mais elevados.

Há, portanto, um tradeoff relacionado a essa mudança ao longo do tempo. A geração corrente sai perdendo, em favor de um aumento de bem estar das gerações futuras. Isso pode racionalizar a resistência que se observa a uma alteração de política desse tipo. No caso $M=3$ vemos comportamentos similares para as principais variáveis, porém o ajuste é mais lento. Consequentemente, a perda da geração corrente é menor, enquanto que as gerações envolvidas na transição ao novo estado estacionário têm seus ganhos reduzidos.

Para ter uma ideia quantitativa do efeito sobre o bem estar das diferentes gerações, seguimos uma estratégia inspirada em Lucas (2003). Especificamente, para cada geração, calculamos quanto a trajetória de consumo na ausência da mudança deveria ser deslocada, a fim de replicar a utilidade obtida como resultado da nova política. De maneira formal, para a geração nascida no período $t$, o impacto sobre $o$ bem estar (em equivalentes de consumo) é $\lambda_{t}$, dado implicitamente por:

$$
U\left[\left(1+\lambda_{t}\right) C_{1 t}^{*},\left(1+\lambda_{t}\right) C_{2 t+1}^{*}\right]=U\left(\widehat{C}_{1 t}, \widehat{C}_{2 t+1}\right),
$$

em que $C_{1 t}^{*}$ e $C_{2 t+1}^{*}$ são os consumos na juventude e na aposentadoria de uma pessoa nascida em $t$, no estado estacionário original (caso a mudança não ocorresse); e $\widehat{C}_{1 t}$ e $\widehat{C}_{2 t+1}$ são esses mesmos consumos, porém na trajetória obtida com a implantação do novo arranjo previdenciário. ${ }^{18}$ A Figura 5 apresenta os valores de $\lambda_{t}$ obtidos a partir das trajetórias correspondentes às duas reformas consideradas $(M=1 \mathrm{e}$ $M=3$ ). Note que, ao contrário da figura anterior, aqui o eixo horizontal indica a geração (identificada por seu período de nascimento) e não o tempo.

Os efeitos de longo prazo são substanciais, correspondendo a um aumento de $22,5 \%$ na trajetória de consumo de uma geração. Os custos associados à transição são também elevados. No caso em que a reforma é feita em um único período $(M=1)$, a geração corrente perde pouco mais que $8 \%$ em termos

\footnotetext{
${ }^{18}$ As variáveis em estado estacionário são também indexadas pelo tempo, pois elas apresentam crescimento de longo prazo por conta do progresso técnico.
} 
Figura 5. Efeito da mudança previdenciário sobre bem estar.

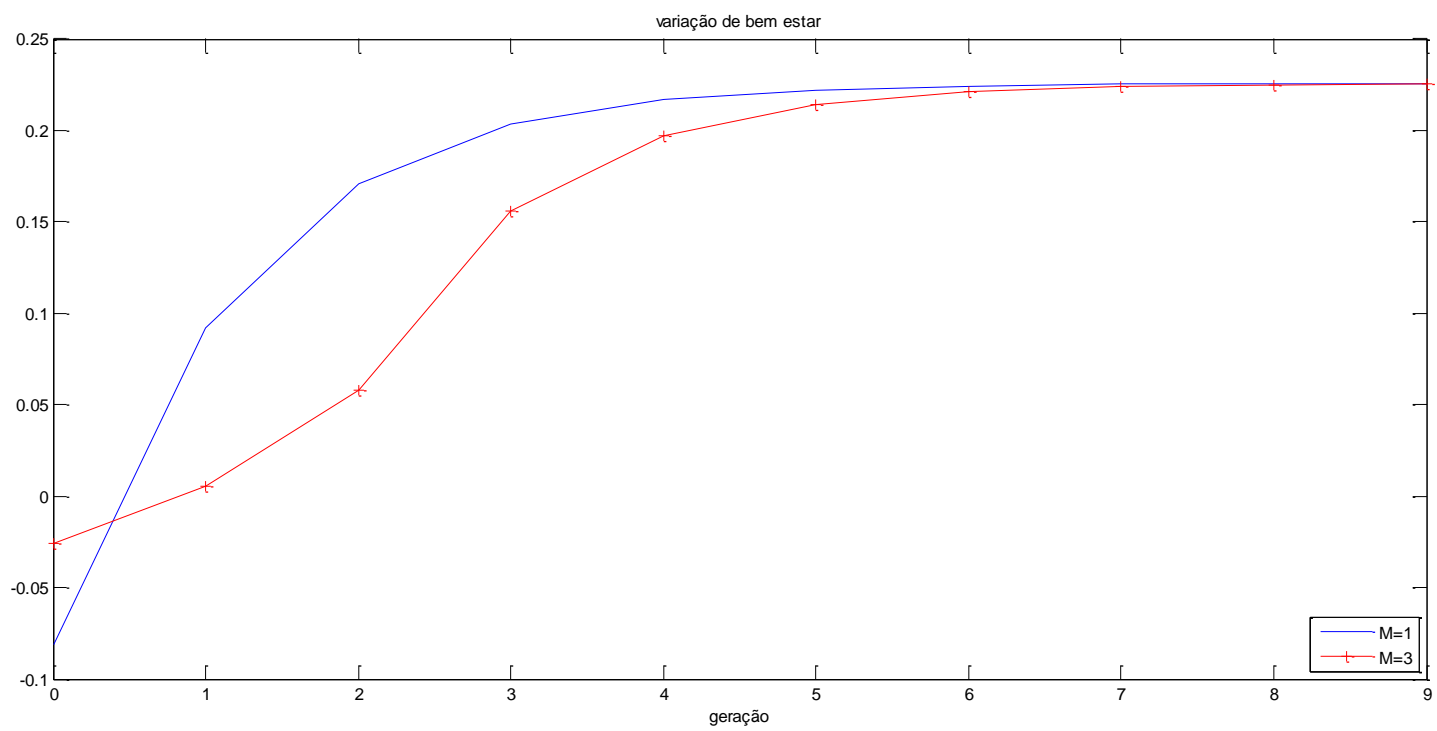

da trajetória de consumo do estado estacionário inicial. Entretanto, já na segunda geração observamos ganhos significativos, da ordem de $9 \%$.

Na simulação de reforma gradual $(M=3)$, os custos são espalhados ao longo do tempo. A perda da geração atual se reduz bastante $\left(\lambda_{0}=2,5 \%\right.$ ), enquanto que os ganhos ao longo da transição são também menores. Por exemplo, o ganho da geração nascida em $t=1$ diminui para $0,55 \%$.

\section{CONCLUSÃO}

Este artigo buscou entender como dois fatos característicos da economia brasileira se relacionam — taxa de juros real entre as maiores do mundo, e elevados gastos em previdência social sob um regime de repartição. Para tal recorremos a um modelo de gerações sobrepostas padrão com um sistema de previdência misto - parte repartição e parte capitalização. Calibramos o modelo para replicar algumas estatísticas brasileiras no período 2000-2014, inclusive o nível da taxa de juros real. Consideramos um estado estacionário com um sistema inteiramente do tipo repartição, sendo as transferências previdenciárias fixadas de modo a reproduzir os gastos em previdência como proporção do PIB no Brasil.

Simulamos então uma reforma no sistema, reduzindo drasticamente a parte de repartição do modelo com vistas a replicar os gastos em previdência do Chile, porém mantendo constantes todos os demais parâmetros. O Chile, como o Brasil, é um país de latino-americano de renda média, porém seu sistema de previdência é majoritariamente do tipo capitalização. A alteração incentiva a poupança e acumulação de capital, reduzindo a produtividade marginal desse insumo e, consequentemente, a taxa de juros.

Em nossa configuração preferida de parâmetros, obtém-se uma diminuição de cerca de 1 ponto percentual na taxa de juros real de longo prazo (ao ano). Isso corresponde a $18 \%$ da diferença média entre as taxas de juros reais de Brasil e Chile no período 2000-2014. Trata-se, portanto, de um efeito relevante. No entanto, uma fração grande dessa discrepância permanece inexplicada pelo modelo, o que sugere a importância de outros canais para entender por que a taxa de juros real brasileira é tão alta. 


\section{REFERÊNCIAS BIBLIOGRÁFICAS}

Acemoglu, D. (2008). Introduction to modern economic growth. Princeton University Press.

Afanasieff, T. S., Lhacer, P. M. V. \& Nakane, M. I. (2002). The determinants of bank interest spread in Brazil. Money Affairs, XV(2), 183-207. Disponível em: http://www.cemla.org/PDF/moneyaffairs/pub_monaff_xv_2.pdf

Almeida, F. D., \& Divino, J. A. (2015). Determinants of the banking spread in the Brazilian economy: The role of micro and macroeconomic factors. International Review of Economics \& Finance, 40, 29-39. doi: 10.1016/j.iref.2015.02.003

Arida, P., Bacha, E. L. \& Lara-Resende, A. (2005). Credit, interest, and jurisdictional uncertainty: Conjectures on the case of Brazil. In F. Giavazzi, I. Goldfajn \& S. Herrera (Eds.), Inflation targeting, debt, and the Brazilian experience, 1999 to 2003 (pp. 265-293). The MIT Press.

Bacha, E. L. (2010). Além da tríade: Há como reduzir os juros? (Texto para Discussão $\mathrm{N}^{0}$ 17). Rio de Janeiro, RJ: Instituto de Estudos de Política Econômica/Casa das Garças (IEPE/CdG). Disponível em: http://iepecdg.com .br/wp-content/uploads/2016/03/101020EdmarCOMO_REDUZIR_OS_JUROS.pdf

Bacha, E. L., Holland, M. \& Gonçalves, F. M. (2007). Is Brazil different? Risk, dollarization, and interest rates in emerging markets (IMF Working Paper $\left.\mathrm{N}^{0} \mathrm{WP} / 07 / 294\right)$. International Monetary Fund. Disponível em: https://www.imf.org/external/pubs/ft/wp/2007/wp07294.pdf

Barboza, R. d. M. (2015). Taxa de juros e mecanismos de transmissão da política monetária no Brasil. Revista de Economia Política, 35(1), 133-155. doi: 10.1590/0101-31572015v35n01a08

Blanchard, O. J., \& Fischer, S. (1989). Lectures on macroeconomics. The MIT Press.

Caetano, M. A.-R., \& Miranda, R. B. (2007, setembro). Comparativo internacional para a previdência social (Texto para Discussão N ${ }^{0}$ 1302). Brasília·DF: Instituto de Pesquisa Econômica Aplicada (IPEA). Disponível em: http://www.ipea.gov.br/portal/index.php?option =com_content\&view $=$ article\&id $=4866$

Cooley, T. F., \& Prescott, E. C. (1995). Economic growth and business cycles. In T. F. Cooley (Ed.), Frontiers of business cycle research (pp. 1-38). Princeton University Press.

Dantas, J. A., de Medeiros, O. R. \& Capelletto, L. R. (2011, maio). Determinantes do spread bancário ex-post no mercado brasileiro (Working Paper $\mathrm{N}^{0}$ 242). Brasília-DF: Banco Central do Brasil. Disponível em: http:// www.bcb.gov.br/pec/wps/port/wps242.pdf

Diamond, P. A. (1965). National debt in a neoclassical growth model. The American Economic Review, 55(5, Part 1), 1126-1150. Disponível em: http://www.jstor.org/stable/1809231

Diamond, P. A. (1993, October). Privatization of social security: Lessons from Chile (Working Paper $\mathrm{N}^{0} 4510$ ). National Bureau of Economic Research (NBER). doi: 10.3386/w4510

Favero, C. A., \& Giavazzi, F. (2002, July). Why are Brazil's interest rates so high? (Working Paper $\left.\mathrm{N}^{0} 224\right)$. Milano, Italy: IGIER - Università Bocconi. Disponível em: http://www.igier.unibocconi.it/folder.php?vedi= $849 \&$ tbn $=$ albero

Franco, G.H.B. (2011). Por que juros tão altos, e o caminho para a normalidade. In G. Franco, A. L. Resende, S. Pessoa \& M. Nakane (Eds.), Por que os juros são altos no Brasil? (pp. 21-57). São Paulo, SP: CPL - Centro de Liderança Pública. Disponível em: http://www.clp.org.br/Show/Por-que-os-juros-sao-altos-no-Brasil-?= LM1iKcl0se1SDdtw6py6wA $==$

Geanakoplos, J. (2008). Overlapping generations model of general equilibrium. In S. N. Durlauf \& L. E. Blume (Eds.), The New Palgrave Dictionary of Economics. Palgrave Macmillan.

Giambiagi, F., \& Tafner, P. (2010). Demografia - a ameaça invisível: O dilema previdenciario que o Brasil se recusa a encarar. Campus - Elsevier.

Giambiagi, F., \& Tafner, P. (2011). Previdência social: Uma agenda de reformas. In E. L. Bacha \& S. Schwartzman (Eds.), Brasil: A nova agenda social (pp. 111-165). Rio de Janeiro: LTC. Disponível em: http:// 
www.schwartzman.org.br/sitesimon/?page_id=2327\&lang=en-us

Gomes, V., Pessôa, S. d. A. \& Veloso, F. A. (2003). Evolução da produtividade total dos fatores na economia brasileira: Uma análise comparativa. Pesquisa e Planejamento Econômico, 33(3), 389-434. Disponível em: http:// ppe.ipea.gov.br/index.php/ppe/article/view/78

Guvenen, F. (2006). Reconciling conflicting evidence on the elasticity of intertemporal substitution: A macroeconomic perspective. Journal of Monetary Economics, 53(7), 1451-1472. doi: 10.1016/j.jmoneco.2005.06.001

Hausmann, R. (2008, September). In search of the chains that hold Brazil back (CID Working Paper $\mathrm{N}^{0} 180$ ). Cambridge, MA: Center for International Development (CID) at Harvard University. Disponível em: https:// www.hks.harvard.edu/centers/cid/publications/faculty-working-papers/cid-working-paper-no--180

Jones, L., Manuelli, R. \& Siu, H. (2000, April). Growth and business cycles (Working Paper $\mathrm{N}^{0}$ 7633). National Bureau of Economic Research (NBER). doi: 10.3386/w7633

Kritzer, B. E. (2008). Chile’s next generation pension reform. Social Security Bulletin, 68(2), 69-84. Disponível em: https://www.ssa.gov/policy/docs/ssb/v68n2/v68n2p69.html

Lucas, R. E., Jr. (2003). Macroeconomic priorities. The American Economic Review, 93(1), 1-14. Disponível em: http://www.jstor.org/stable/3132159

Pessoa, S., \& Nakane, M. (2011). O processo de formação da taxa de juros no Brasil. In G. Franco, A. L. Resende, S. Pessoa \& M. Nakane (Eds.), Por que os juros são altos no Brasil? (pp. 59-93). São Paulo, SP: CPL - Centro de Liderança Pública. Disponível em: http://www.clp.org.br/Show/Por-que-os-juros-sao-altos-no-Brasil-?= LM1iKcl0se1SDdtw6py6wA $==$

Rocha, R.d.R., \& Caetano, M. A.-R. (2008, março). O sistema previdenciário brasileiro: Uma avaliação de desempenho comparada (Texto para Discussão $\mathrm{N}^{0}$ 1331). Brasília·DF: Instituto de Pesquisa Econômica Aplicada (IPEA). Disponível em: http://www.ipea.gov.br/portal/index.php?option=com_content\&view $=$ article\&id $=4887$

Romer, D. (2006). Advanced macroeconomics (3 ed.). McGraw-Hill.

Samuelson, P. A. (1958). An exact consumption-loan model of interest with or without the social contrivance of money. Journal of Political Economy, 66(6), 467-482. doi: 10.1086/258100

Segura-Ubiergo, A. (2012, February). The puzzle of Brazil's high interest rates (IMF Working Paper $\left.\mathrm{N}^{0} \mathrm{WP} / 12 / 62\right)$. International Monetary Fund. Disponível em: https://www.imf.org/external/pubs/ft/wp/2012/wp1262.pdf

Souza-Sobrinho, N. F. (2010). Macroeconomics of bank interest spreads: Evidence from Brazil. Annals of Finance, 6(1), 1-32. doi: 10.1007/s10436-009-0131-0

Tafner, P. (2012). Desafios e reformas da previdência social brasileira. Revista USP, 93, 137-156. doi: 10.11606/issn.2316-9036.v0i93p137-156 


\section{APÊNDICE.}

Varíaveis com asterisco denotam estado estacionário. Primeiramente note, da função de produção, que o produto por trabalhador-eficiência é dado por $y=Y /(A N)=k^{\alpha}$. A razão capital-produto é então $k / y=k^{1-\alpha}$. Usando as equações (3) e (5), pode-se então escrever a taxa de juros de estado estacionário da seguinte forma:

$$
R^{*}=\alpha k^{* \alpha-1}-\delta=\frac{\alpha}{k^{*} / y^{*}}-\delta,
$$

de onde segue que a razão capital-produto é

$$
\frac{k^{*}}{y^{*}}=\frac{\alpha}{R^{*}+\delta}
$$

Usando a equação (14) em estado estacionário, com $\tau^{p}$ constante no tempo, temos que

$$
\frac{k^{*}}{y^{*}}=\frac{k^{*}}{k^{* \alpha}}=\frac{1-\alpha}{(1+n)(1+g)}\left[\frac{\left(1-\tau^{p}\right)\left(\frac{\alpha k^{* \alpha-1}+(1-\delta)}{1+\theta}\right)^{1 / \gamma}-\tau^{p}(1+n)(1+g)}{\left(\alpha k^{* \alpha-1}+1-\delta\right)+\left(\frac{\alpha k^{* \alpha-1}+(1-\delta)}{1+\theta}\right)^{1 / \gamma}}\right] .
$$

Substituindo (A-1) em (A-3), segue que

$$
\frac{k^{*}}{y^{*}}=\frac{1-\alpha}{(1+n)(1+g)}\left[\frac{\left(1-\tau^{p}\right)\left(\frac{1+R^{*}}{1+\theta}\right)^{1 / \gamma}-\tau^{p}(1+n)(1+g)}{\left(1+R^{*}\right)+\left(\frac{1+R^{*}}{1+\theta}\right)^{1 / \gamma}}\right] .
$$

Igualando (A-2) e (A-4):

$$
\frac{\alpha}{R^{*}+\delta}=\frac{1-\alpha}{(1+n)(1+g)}\left[\frac{\left(1-\tau^{p}\right)\left(\frac{1+R^{*}}{1+\theta}\right)^{1 / \gamma}-\tau^{p}(1+n)(1+g)}{\left(1+R^{*}\right)+\left(\frac{1+R^{*}}{1+\theta}\right)^{1 / \gamma}}\right]
$$

Resolvendo para $\theta$ temos:

$$
\theta=\left(1+R^{*}\right)\left[\frac{\left(1-\tau^{p}\right)-\frac{\alpha}{R^{*}+\delta} \frac{(1+n)(1+g)}{1-\alpha}}{\tau^{p}(1+n)(1+g)+\frac{\alpha\left(1+R^{*}\right)}{R^{*}+\delta} \frac{(1+n)(1+g)}{1-\alpha}}\right]^{\gamma}-1
$$

O valor de $\theta$ é então calibrado de modo a reproduzir a taxa de juros $R^{*}$ como nos dados. No caso, como cada período no modelo corresponde a 30 anos, o valor de $R^{*}$ utilizado é $(1+0,0697)^{30}-1=6,5485$, que equivale a uma taxa de juros anual de $6,97 \%$. 